\title{
HOW TO USE THE Portuguese Memory Book
}

Each jingle in this book gives you two pieces of information about a Portuguese word: 1 ) its sound (pronunciation, including stress, or accent), and 2) its sense (meaning). The jingle uses the word in a natural setting that helps you store in your memory both the sound and the sense of the word. You need not memorize an entire lyric. Just remember the significant parts.

The following jingle will show you how the method works.

noite (f.) night

Don't annoy Chihuahuas in the night.

If you ignore their bark, you'll feel their bite.

The Portuguese word to be learned is noite. The English equivalent of noite is "night," which is in boldface type in the jingle. The sound of noite is given by the last syllable of annoy plus the first syllable of Chihuahua. In the jingle, the syllables noy and Chi are printed in boldface type and underscored. These two syllables, read together, spell out the sound of the complete Portuguese word noite. Note that here, as always in this book, the English sounds used to spell out the sound of the Portuguese word are consecutive. That makes them easy to recognize and to remember. The meter for each jingle was chosen so that the accent falls on the stressed syllable of the Portuguese word. 
Here is another example:

coelho rabbit

That quail you see has non-fowl habits.

She likes to play around with rabbits.

The sound and stress of Portuguese coelho are given by quail plus you. 